\title{
INVESTIGATION ON THREE POINT FLEXURAL STRENGTH OF ALKALINE TREATED BANANA FIBER REINFORCED CARDANOL RESIN POLYMER COMPOSITES BY RESPONSE SURFACE METHODOLOGY
}

\author{
A. PARRE ${ }^{1}$, B. KARTHIKEYAN ${ }^{2}$, A. BALAJI ${ }^{3} \&$ R.UDHAYASANKAR ${ }^{4}$ \\ ${ }^{1}$ Research scholar, Department of Mechanical Engineering, Faculty of Engineering and Technology, \\ Annamalai University, Tamil Nadu, India \\ ${ }^{2}$ Professor, Department of Mechanical Engineering, Faculty of Engineering and Technology, Annamalai University, \\ Tamil Nadu, India \\ ${ }^{3}$ Associate Professor, Department of Mechanical Engineering, A.V.C College of Engineering, Mayiladuthurai, \\ Tamil Nadu, India \\ ${ }^{4}$ Assistant Professor Professor, Department of Mechanical Engineering, Faculty of Engineering and Technology,
} Annamalai University, Tamil Nadu, India composite matrix. Locally harvested banana fiber was cut into an average length of 5, 10, 15, 20 and 25 mm and then processed with alkali at varying concentrations of $1,3,5,7 \& 9$ percent $\mathrm{NaOH}$. The aim of the study is to investigate the maximum flexural strength of Alkaline Treated Banana Fiber Reinforced Cardonal Resin (ATBF/CR) Biocomposites. ATBF/CR is fabricated and evaluated the process by using Minitab 17 software with 3 variables and 5 levels with well known technique Response Surface Methodology (RSM) - Central Composite Design (CCD) in order to attain the optimum flexural strength of 47.25 MPa for our ATBF/CR Biocomposites.

KEYWORDS: Natural Fiber, Alkaline Treated Banana Fiber, Biopolymer, Polymer Composites, Response Surface Methodology.
\end{abstract}

Received: Jun 09, 2020; Accepted: Jun 29, 2020; Published: Sep 26, 2020; Paper Id.: IJMPERDJUN20201436

\section{INTRODUCTION}

Natural fibers for biocomposites are usually sourced from various plants like hemp, coir pineapple sisal, jute, banana and flax. The biocomposites made from such natural fibers are also called Green composites since they are biodegradable and environment friendly. Recent studies have been shown the importance of natural fibers in global sustainability [1]. Apart from environmental advantages they also being liked for its excellent mechanical properties, low density and low cost. The growing demand of biofibers attracted us to do the research on mechanical and thermal properties of ATBF/CR biocomposites. Using natural fibers as a reinforcement material has many advantages like reduced wear of the tools during process, safe for health and eco-friendly [2, 3]. Banana fiber reinforced biocomposites are most suitable for manufacturing automobile interiors as they are light weight and provide high flexural strength [4]. We have chosen Alkali treatment technique to make the fiber surface more suitable for binding with the matrix by removing unwanted impurities on the surface [5]. Treating the fiber with Sodium hydroxide and silane increases its flexural strength to a great extent [6]. Alkali treatment removes the hemicellulose impurity present in the fiber and helps forming better crystalinity of the fiber and binds strongly to 
the matrix. Through this treatment we attain higher elongation of the fiber [7]. As we are making biocomposites it makes sense to use bioresins instead of synthetic resins. By using bioresins we are getting rid of health hazards, handling issues and toxicity. So we have chosen cashew nut shell liquid (CNSL) which is a bioresin and it is renewable, sustainable, low cost and environmental safe $[8,9]$. In the forthcoming days it is believed that petroleum based polymers would be substituted with bio based polymers to a great proportion for its eco friendliness and cost effectiveness [11, 12]. Manufacturing and Engineering industries has been using biocomposite materials for many decades in various products for its cost effectiveness, good strength, high flexibility, biodegradable nature, etc [13]. Hence we proposed to plan our study by using a method Design of Experiment (DOE).

DOE is a branch of applied statistics used in experiments which involve multiple independent variables (input). This method is being used successfully in manufacturing processes for optimizing the desired dependent variable (output). DOE helps right from planning to interpretation of the controlled experiments. It analyses various input factors and interprets their involvement in each experiment. So, it facilitates the user to get the desired output by allowing the user to go for using various combinations of parameters under a set of experiments [14, 15]. RSM is used to conduct test at various levels and factors as well as it clearly determines the interactions of independent variables (input factors) and optimizes the response variables while saving time and cost by reducing the number of trials $[16,17]$. CCD is a standard, effective, and the most commonly used design of RSM. The effect of critical factors is well investigated in this method. Therefore, we use CCDbased RSM to assign the individual variables to a range of evaluations by means of a rationalized number of design points along with a reliable curvature estimate to obtain a reasonable amount of information for insufficient testing [18].

The aim of this work were: (1) to synthesize $\mathrm{f}$ the biopolymer cardanol resin, from CSNL; (2) to cut banana fiber (5, 10, 15, 20, \& 25 mm length); (3) Banana fibre treated to $\mathrm{NaOH}(1,3,5,7, \& 9 \%)$ (4) To manufacture cardanol resin biocomposite materials using banana fibers as a reinforcement in fifteen different samples (varying fiber length, weight percentage and treated $\mathrm{NaOH} \%$ ); (4) to examine the flexural strength of the biocomposite materials and attain optimum flexural strength using RSM.

\section{EXPERIMENTAL PROCEDURES}

\subsection{Materials}

Banana fiber was brought to Erode, Tamil Nadu, India from the supplier 'Sri Achu Fibres' Sodium hydroxide (NaOH) from the vendor, Mayiladuthurai, Tamil Nadu, India.

\subsection{Preparation of Banana Fibers}

The extracted banana fiber was dried in sunlight for 2 days, then in a hot air oven for 24 hours at 80 to $90{ }^{\circ} \mathrm{C}$ to eliminate moisture content. Subsequently, the fibers were cut into 5, 10, 15, 20 and $25 \mathrm{~mm}$ length transversely. The dry banana leaf fibers have been individually absorbed at room temperature in 1, 3, 5, 7, and $9 \% \mathrm{NaOH}$ (weight percent banana fiber) for 24 hours. The fibers were then dipped with distilled water to get rid of any $\mathrm{NaOH}$ particles on the exterior part of fibers [19]. The dehydrated banana fibers were kept underneath the sunlight for two more days and set aside in hot air oven at $90-100^{\circ}$ C for 24 hrs to take away the humidity [20, 21].

\subsection{Preparation of Cardanol Resin}

Cardanol and formaldehydes were used to synthesise the cardanol/formaldehyde resin with molar ratios ( $\{\mathrm{CNSL}: \mathrm{HCHO}: \mathrm{KOH}\},\{1: 1.6: 0.136\})$ by means of Potassium Hydroxide $(\mathrm{KOH})$ as catalyst was originally dissolved in 
CNSL with a magnetic stirrer at $300 \mathrm{rpm}$ for about 30 minutes in a glass beaker at $60{ }^{\circ} \mathrm{C}$. Then, along with the mixture about $48 \mathrm{gms}$ of formaldehyde is further added to a glass beaker and located above the magnetic stirrer. Subsequently on complete addition, the reaction kettle should be constantly maintained at $80^{\circ} \mathrm{C}$, and the mixture in the vessel should be thoroughly stirred at this temperature for almost 1 hour until it becomes homogenous with mud colour [22]. Then the mixed resin was poured in a two neck flat bottomed flask attached with a condenser and thermometer. The resin was constantly stirred, refluxed and heated to a temperature range of $100-120^{\circ} \mathrm{C}$ for $3 \mathrm{hrs}$ followed by cooling at normal room temperature [22]. Fig. 1 shows synthesize of biopolymer cardanol resin. Cardanol resin was confirmed by Fourier Transform-Infrared (FT-IR) Spectroscopy. Fig. 2 demonstrates how Cardanol resin formulation reacts.
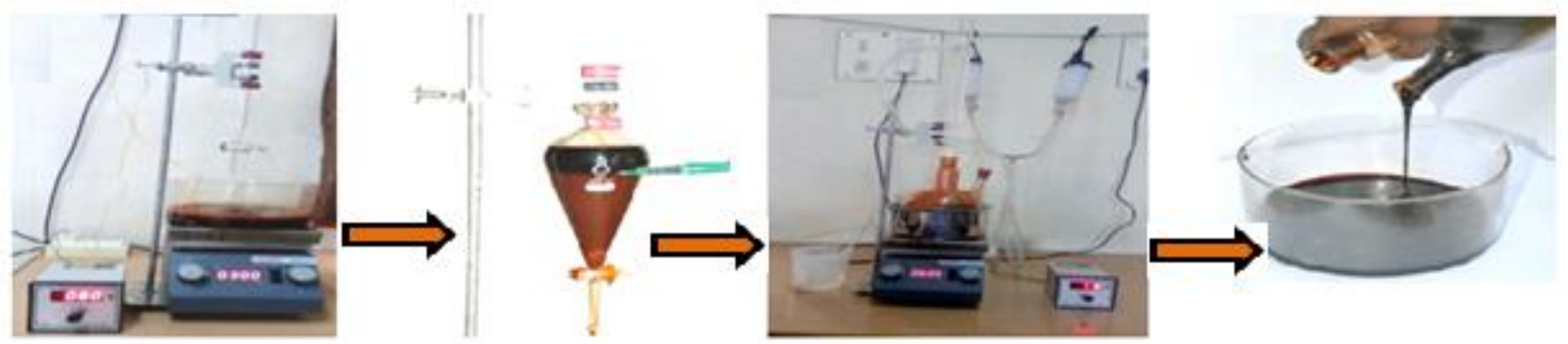

Figure 1: Synthesize of Cardanol - Resin

\subsection{FT-IR Analysis of Cardanol Resin}

The FT-IR range (Fig. 2) of the sample was examined intricately. The O-H group vibrations are probably going to be the touchiest to nature and they show articulated movements in the spectra of the hydrogen-fortified species. For the most part, hydrogen bond free $\mathrm{O}-\mathrm{H}$ extending recurrence will be seen around $3700 \mathrm{~cm}^{-1}$ [23]. An expansive range at $3345 \mathrm{~cm}^{-1}$ shows the move of $\mathrm{O}-\mathrm{H}$ extending vibration which demonstrates the nearness of intermolecular hydrogen holding [2]. Additionally a little top at $3420 \mathrm{~cm}^{-1}$ shows the nearness of minor measure of hydrogen bond free phenolic $\mathrm{O}-\mathrm{H}$ gathering. The solid tops at 3009 and $2924 \mathrm{~cm}^{-1}$ fortify the nearness of $\mathrm{CH}_{2}$ extending in the cardanol and formaldehyde bunch individually. The medium groups at 1588 and $1456 \mathrm{~cm}^{-1}$ demonstrate the nearness of even extending $\mathrm{C}=\mathrm{C}$ securities and moderate tops at 1267 and $1151 \mathrm{~cm}^{-1}$ shows the nearness of $\mathrm{C}-\mathrm{C}$ extending recurrence. A top almost $1084 \mathrm{~cm}^{-1}$ relates to the nearness of $\mathrm{C}-\mathrm{O}$ extending recurrence. A solid band seen at $906 \mathrm{~cm}-1$ demonstrates the $\mathrm{C}-\mathrm{H}$ out plane bowing vibration. A solid top at 781 $\mathrm{cm}^{-1} \mathrm{C}-\mathrm{C}-\mathrm{C}$ expresses the presence of in-plane twisting of aromatic ring.

\subsection{Testing Standards}

The Flexural measurement experiments were performed on Universal Testing Machine (UTM Model: UNITEK 94100). For flexural tests, the ATBF/CR biocomposites samples were cut into pieces with cross sectional dimension of specimen $127 \times 13 \times 3 \mathrm{~mm}$ in accordance with 3 point bend test by ASTM D 790. Moreover span length is of $40 \mathrm{~mm}$ and a cross head speed of $2 \mathrm{~mm} / \mathrm{min}$ for a $64 \mathrm{~mm}$ gap was maintained. The testing process involved by placing the test specimen and applies force to it until it fractures and breaks. 


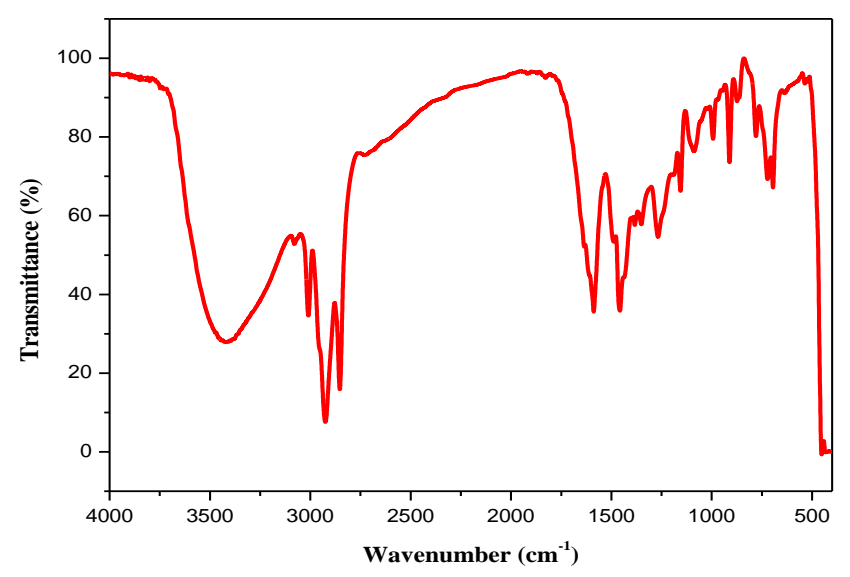

Figure 2 : FT-IR Spectra of Cardanol Resin

\section{Experimental design}

DOE is one of the most reliable tools which analyses various given inputs of a process with systematic, statistical techniques and provides us with most desirable, optimized result. RSM is one of the techniques of DOE which is widely used in new product designing, improving or optimizing existing design or process and there by obtaining the desired levels of performance [24]. ATBF/CR biocomposites were prepared based on the experimental design using compression moulding process. Then each biocomposites with all possible combinations of input variables was thoroughly investigated by using Minitab 17 software for the optimal result. The analysis is done according to CCD of RSM. The selected 3 factors and 5 variation levels were shown in Table 1 and also the general form of response surface model is shown in equation 1.

Table 1: Framework for Experimental design of ATBF/CR Biocomposites

\begin{tabular}{|c|c|c|c|c|c|c|}
\hline \multirow{2}{*}{ Factors } & \multirow{2}{*}{ Symbols } & \multicolumn{5}{|c|}{ Variation Levels } \\
\cline { 3 - 7 } & & Low (-1.633) & $\mathbf{( - 1 )}$ & Medium (0) & $(+\mathbf{1})$ & High(+1.633) \\
\hline Fiber weight (\%) & $\mathrm{X}_{1}$ & 5 & 10 & 15 & 20 & 25 \\
\hline Fiber length (mm) & $\mathrm{X}_{2}$ & 5 & 10 & 15 & 20 & 25 \\
\hline $\mathrm{NaOH}$ treatment (\%) & $\mathrm{X}_{3}$ & 1 & 3 & 5 & 7 & 9 \\
\hline
\end{tabular}

Table 2 : Coded Values by Central Composite Design

\begin{tabular}{|c|c|c|c|c|c|c|}
\hline $\begin{array}{c}\text { Tes } \\
\mathbf{t} \\
\text { no }\end{array}$ & \multicolumn{3}{|c|}{ Variables (Coded value) } & \multicolumn{3}{c|}{ Variables (Real value) } \\
\hline & $\begin{array}{c}\text { Fiber } \\
\text { Weight } \\
(\%)\end{array}$ & $\begin{array}{c}\text { Fiber } \\
\text { Length } \\
(\mathrm{mm})\end{array}$ & $\begin{array}{c}\text { NaOH } \\
\text { Treatment } \\
(\%)\end{array}$ & $\begin{array}{c}\text { Fiber } \\
\text { Weigh } \\
\text { t } \%)\end{array}$ & $\begin{array}{c}\text { Fiber } \\
\text { Length } \\
(\mathrm{mm})\end{array}$ & $\begin{array}{c}\text { NaOH } \\
\text { Treatment } \\
(\%)\end{array}$ \\
\hline 1 & 1.000 & -1.000 & -1.000 & 20 & 10 & 3 \\
\hline 2 & 0.000 & 0.000 & 0.000 & 15 & 15 & 5 \\
\hline 3 & 1.000 & 1.000 & 1.000 & 20 & 20 & 7 \\
\hline 4 & 0.000 & 0.000 & 0.000 & 15 & 15 & 5 \\
\hline 5 & -1.000 & 1.000 & -1.000 & 10 & 20 & 3 \\
\hline 6 & -1.000 & -1.000 & 1.000 & 10 & 10 & 7 \\
\hline 7 & 0.000 & 0.000 & -1.633 & 15 & 15 & 1 \\
\hline 8 & 0.000 & 1.633 & 0.000 & 15 & 25 & 5 \\
\hline 9 & 1.633 & 0.000 & 0.000 & 25 & 15 & 5 \\
\hline
\end{tabular}



Cardanol Resin Polymer Composites By Response Surface Methodology

\begin{tabular}{|c|c|c|c|c|c|c|}
\hline 10 & -1.633 & 0.000 & 0.000 & 5 & 15 & 5 \\
\hline 11 & 0.000 & 0.000 & 1.633 & 15 & 15 & 9 \\
\hline 12 & 0.000 & -1.633 & 0.000 & 15 & 5 & 5 \\
\hline 13 & 0.000 & 0.000 & 0.000 & 15 & 15 & 5 \\
\hline 14 & 0.000 & 0.000 & 0.000 & 15 & 15 & 5 \\
\hline 15 & -1.000 & -1.000 & -1.000 & 10 & 10 & 3 \\
\hline 16 & 0.000 & 0.000 & 0.000 & 15 & 15 & 5 \\
\hline 17 & 0.000 & 0.000 & 0.000 & 15 & 15 & 5 \\
\hline 18 & 1.000 & -1.000 & 1.000 & 20 & 10 & 7 \\
\hline 19 & 1.000 & 1.000 & -1.000 & 20 & 20 & 3 \\
\hline 20 & -1.000 & 1.000 & 1.000 & 10 & 20 & 7 \\
\hline
\end{tabular}

\subsection{Fabrication of ATBF/CR biocomposites}

The mixed components was taken and moulded by using compression moulding process. The outer surface of the moulds was encrusted with the help of wax in order to stay away from sticking together of the components and to permit effortless removing of composites. Then the mixture was then stretched consistently on the plane of the moulds with the size of $300 \times 300 \times 3 \mathrm{~mm}$ plates [22]. The mould was then kept closed at the pressure of $10 \mathrm{~N} / \mathrm{mm}^{2}$ by maintaining at $70-90{ }^{\circ} \mathrm{C}$ for about 30 minutes [20]. Subsequently all the fifteen specimens were kept and maintained at $70{ }^{\circ} \mathrm{C}$ for $12 \mathrm{hrs} \mathrm{in} \mathrm{hot} \mathrm{air} \mathrm{oven.}$ Table 3 shows designations and detailed compositions of the ATBF/CR biocomposites. Fig. 3 shows photograph of the developed ATBF/CR biocomposites.
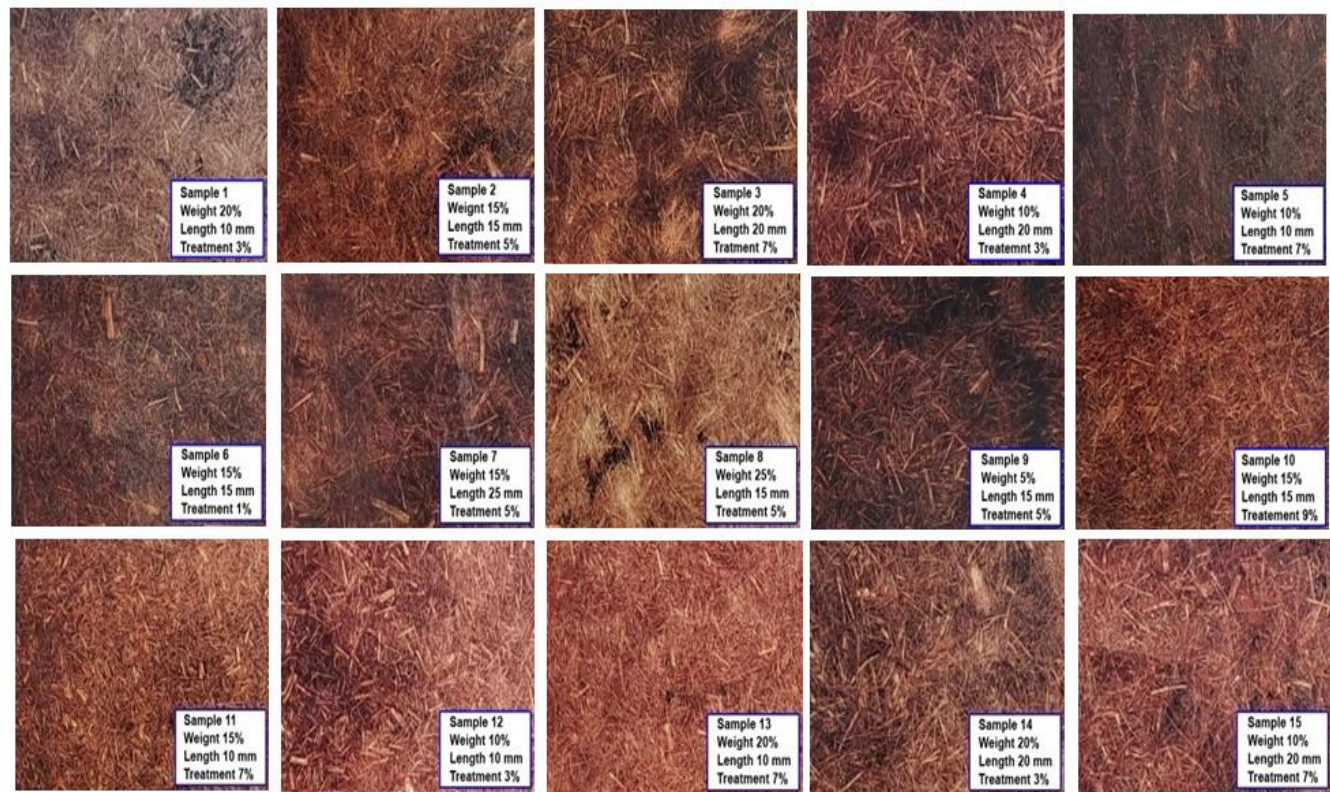

Figure 3 : Fabricated samples of ATBF/CR biocomposites ( $S_{1}$ toS15)

Table 3: Designations and Detailed Compositions of the ATBF/CR biocomposites

\begin{tabular}{|c|c|c|c|c|}
\hline \multirow{2}{*}{ Sample } & \multirow{2}{*}{ Matrix } & \multicolumn{3}{|c|}{ Reinforcement Variables (Banana fiber) } \\
\cline { 3 - 5 } & & $\begin{array}{c}\text { Fiber Weight } \\
(\mathbf{\%})\end{array}$ & $\begin{array}{c}\text { Fiber Length } \\
(\mathbf{m m})\end{array}$ & NaOH Treatment (\%) \\
\hline $\mathrm{S}_{1}$ & Cardanol & 20 & 10 & 3 \\
\hline $\mathrm{S}_{2}$ & Cardanol & 15 & 15 & 5 \\
\hline $\mathrm{S}_{3}$ & Cardanol & 20 & 20 & 7 \\
\hline $\mathrm{S}_{4}$ & Cardanol & 10 & 20 & 3 \\
\hline $\mathrm{S}_{5}$ & Cardanol & 10 & 10 & 7 \\
\hline $\mathrm{S}_{6}$ & Cardanol & 15 & 15 & 1 \\
\hline
\end{tabular}




\begin{tabular}{|l|l|c|c|c|}
\hline $\mathrm{S}_{7}$ & Cardanol & 15 & 25 & 5 \\
\hline $\mathrm{S}_{8}$ & Cardanol & 25 & 15 & 5 \\
\hline $\mathrm{S}_{9}$ & Cardanol & 5 & 15 & 5 \\
\hline $\mathrm{S}_{10}$ & Cardanol & 15 & 15 & 9 \\
\hline $\mathrm{S}_{11}$ & Cardanol & 15 & 5 & 5 \\
\hline $\mathrm{S}_{12}$ & Cardanol & 10 & 10 & 3 \\
\hline $\mathrm{S}_{13}$ & Cardanol & 20 & 10 & 7 \\
\hline $\mathrm{S}_{14}$ & Cardanol & 20 & 20 & 3 \\
\hline $\mathrm{S}_{15}$ & Cardanol & 10 & 20 & 7 \\
\hline
\end{tabular}

\section{RESULTS AND DISCUSSION}

Table 4 : Experimental design and Results of the Central Composite Design- Regression Equation in Uncoded Units

\begin{tabular}{|c|c|c|c|c|c|}
\hline \multirow[b]{2}{*}{$\begin{array}{l}\text { Sl. } \\
\text { No. }\end{array}$} & \multicolumn{3}{|c|}{ Independent Variables } & \multicolumn{2}{|c|}{ Flexural strength (MPa) } \\
\hline & $\begin{array}{c}\text { Fiber Weight } \\
(\%)\end{array}$ & $\begin{array}{l}\text { Fiber Length } \\
\qquad(\mathrm{mm})\end{array}$ & $\begin{array}{c}\mathrm{NaOH} \\
\text { Treatment }(\%)\end{array}$ & Experimental & Predicted \\
\hline 1 & 20 & 10 & 3 & 22 & 20.5881 \\
\hline 2 & 15 & 15 & 5 & 47 & 47.5192 \\
\hline 3 & 20 & 20 & 7 & 32 & 32.1275 \\
\hline 4 & 15 & 15 & 5 & 47 & 47.5192 \\
\hline 5 & 10 & 20 & 3 & 29 & 28.1679 \\
\hline 6 & 10 & 10 & 7 & 21 & 22.0780 \\
\hline 7 & 15 & 15 & 1 & 27 & 29.3143 \\
\hline 8 & 15 & 25 & 5 & 32 & 32.4289 \\
\hline 9 & 25 & 15 & 5 & 24 & 25.1390 \\
\hline 10 & 5 & 15 & 5 & 21 & 20.2648 \\
\hline 11 & 15 & 15 & 9 & 32 & 30.0895 \\
\hline 12 & 15 & 5 & 5 & 25 & 24.9749 \\
\hline 13 & 15 & 15 & 5 & 47 & 46.3943 \\
\hline 14 & 15 & 15 & 5 & 47 & 46.3943 \\
\hline 15 & 10 & 10 & 3 & 24 & 23.6033 \\
\hline 16 & 15 & 15 & 5 & 47 & 47.0192 \\
\hline 17 & 15 & 15 & 5 & 47 & 47.0192 \\
\hline 18 & 20 & 10 & 7 & 26 & 26.5629 \\
\hline 19 & 20 & 20 & 3 & 30 & 28.6528 \\
\hline 20 & 10 & 20 & 7 & 21 & 22.1427 \\
\hline
\end{tabular}

\subsection{Multiple Regression Analysis}

Table 5 : Flexural strength of ATBF/CR biocomposites by Response Surface Quadratic Model

\begin{tabular}{|l|c|r|r|r|c|}
\hline \multicolumn{1}{|c|}{ Source } & DF & \multicolumn{1}{c|}{ Adj SS } & Adj MS & F-Value & P-Value \\
\hline Model & 11 & 2041.04 & 185.55 & 75.12 & 0.000 \\
\hline Blocks & 2 & 4.42 & 2.21 & 0.90 & 0.446 \\
\hline Linear & 3 & 99.90 & 33.30 & 13.48 & 0.002 \\
\hline $\mathrm{X}_{1}$ & 1 & 29.70 & 29.70 & 12.02 & 0.008 \\
\hline $\mathrm{X}_{2}$ & 1 & 69.45 & 69.45 & 28.12 & 0.001 \\
\hline $\mathrm{X}_{3}$ & 1 & 0.75 & 0.75 & 0.30 & 0.596 \\
\hline Square & 3 & 1884.34 & 628.11 & 254.28 & 0.000 \\
\hline $\mathrm{X}_{1} * \mathrm{X}_{1}$ & 1 & 1042.47 & 1042.47 & 422.03 & 0.000 \\
\hline $\mathrm{X}_{2} * \mathrm{X}_{2}$ & 1 & 581.32 & 581.32 & 235.34 & 0.000 \\
\hline $\mathrm{X}_{3} * \mathrm{X}_{3}$ & 1 & 517.47 & 517.47 & 209.49 & 0.000 \\
\hline 2 -way interaction & 3 & 52.38 & 17.46 & 7.07 & 0.012 \\
\hline $\mathrm{X}_{1} * \mathrm{X}_{2}$ & 1 & 10.13 & 10.13 & 4.10 & 0.078 \\
\hline $\mathrm{X}_{1} * \mathrm{X}_{3}$ & 1 & 36.12 & 36.12 & 14.62 & 0.005 \\
\hline $\mathrm{X}_{2} * \mathrm{X}_{3}$ & 1 & 6.13 & 6.13 & 2.48 & 0.154 \\
\hline
\end{tabular}




\begin{tabular}{|l|c|r|r|r|l|}
\hline Error & 8 & 19.76 & 2.47 & & \\
\hline Lack-of-fit & 5 & 19.76 & 3.95 & $*$ & $*$ \\
\hline Pure error & 3 & 0.00 & 0.00 & & \\
\hline Total & $\mathbf{1 9}$ & $\mathbf{2 0 6 0 . 8 0}$ & & & \\
\hline
\end{tabular}

The regression coefficients was analysed by applying CCD to determine the relationships between response and the process parameters in which it was given in the Eq. (2). The results obtained from flexural strength based on predicted and experimental data for each of the sample ATBF/CR biocomposites given in the Table 4.

Flexural strength $(\mathrm{MPa})=46.978+1.492 \mathrm{X}_{1}+2.282 \mathrm{X}_{2}-0.1237 \mathrm{X}_{3}-8.885 \mathrm{X}_{1}^{2}-6.635 \mathrm{X}_{2}^{2}-$

$$
6.260 \mathrm{X}_{3}^{2}+1.125 \mathrm{X}_{1} \mathrm{X}_{2}+2.125 \mathrm{X}_{1} \mathrm{X}_{3}-0.6875 \mathrm{X}_{2} \mathrm{X}_{3}
$$

Where $X_{1}, X_{2}, X_{3}$ are the coded values of the independent variables Fiber Weight $X_{1}$, Fiber length $X_{2}$ and $\mathrm{NaOH}$ treatment $X_{3}$ respectively.

Table 4 represents the experimental results obtained from RSM flexural strength at different various combinations of ATBF/CR composites. RSM was used in my earlier study to compare the tensile strength of various mixture of ATBF/CR emphasize the biocomposites whereas, now, the same method RSM is used again to refer the flexural properties of banana fibre [25].

Table 5 represents the various factors of $\mathrm{ATBF} / \mathrm{CR}$ composites are significant with $\mathrm{p}$ value $<0.05$. The linear interaction shows $X_{1}$ and $X_{2}$ are significant with $p$ value 0.008 and 0.001 whereas $X_{3}$ is not significant but when comparing with squared interaction all the factors such as $\mathrm{X}_{1}^{2}, \mathrm{X}_{2}^{2}$ and $\mathrm{X}_{3}{ }^{2}$ are showing perfect association with $\mathrm{p}$ value <0.01.In two way interaction the combination $\mathrm{X}_{1} * \mathrm{X}_{2}$ are closer to significance whereas $\mathrm{X}_{1} * \mathrm{X}_{3}$ interaction shows strong association with $\mathrm{p}$ value 0.005 but there is no significance with $\mathrm{X}_{2 *} \mathrm{X}_{3}$. For the mechanical properties of flexural strength confirm that the predicted model and experimental data were in good agreement. Table 6 shows that Variance Inflation Factor (VIF) values of all composite factors are closer to 1 which indicates that there is strong association between the variables.

Table 6 : Coded Coefficients for ATBF/CR biocomposites

\begin{tabular}{|c|c|c|c|c|c|c|}
\hline Term & Effect & Coef & SE Coef & T-Value & P-Value & VIF \\
\hline Constant & & $\mathbf{4 6 . 9 7 8}$ & $\mathbf{0 . 6 4 1}$ & $\mathbf{7 3 . 2 9}$ & $\mathbf{0 . 0 0 0}$ & \\
\hline \multicolumn{7}{|c|}{ Blocks } \\
\hline 1 & & 0.042 & 0.513 & 0.08 & 0.937 & 1.47 \\
\hline 2 & & 0.542 & 0.513 & 1.06 & 0.322 & 1.47 \\
\hline $\mathrm{X}_{1}$ & 2.985 & 1.492 & 0.430 & 3.47 & 0.008 & 1.00 \\
\hline $\mathrm{X}_{2}$ & 4.565 & 2.282 & 0.430 & 5.30 & 0.001 & 1.00 \\
\hline $\mathrm{X}_{3}$ & 0.475 & 0.237 & 0.430 & 0.55 & 0.596 & 1.00 \\
\hline $\mathrm{X}_{1} * \mathrm{X}_{1}$ & -17.769 & -8.885 & 0.432 & -20.54 & 0.000 & 1.01 \\
\hline $\mathrm{X}_{2} * \mathrm{X}_{2}$ & -13.269 & -6.635 & 0.432 & -15.34 & 0.000 & 1.01 \\
\hline $\mathrm{X}_{3} * \mathrm{X}_{3}$ & -12.519 & -6.260 & 0.432 & -14.47 & 0.000 & 1.01 \\
\hline $\mathrm{X}_{1} * \mathrm{X}_{2}$ & 2.250 & 1.125 & 0.556 & 2.02 & 0.078 & 1.00 \\
\hline $\mathrm{X}_{1} * \mathrm{X}_{3}$ & 4.250 & 2.125 & 0.556 & 3.82 & 0.005 & 1.00 \\
\hline $\mathrm{X}_{2} * \mathrm{X}_{3}$ & -1.750 & -0.875 & 0.556 & -1.57 & 0.154 & 1.00 \\
\hline $\mathrm{R}-\mathrm{sq}(\mathrm{pred})=86.28 \%$ &
\end{tabular}

The value of $\mathrm{R}^{2}$ for the predicted model shows $86.28 \%$ for the mechanical properties of Flexural Strength, confirms that the predicted model and experimental data were in good agreement. 
The standard likelihood plots for the ATBF / CR biocomposites as seen in Fig.4 shows the findings for the $\mathrm{R}_{2}$ value suggest strong consistency within the context of experiment between the measured and observed effects.

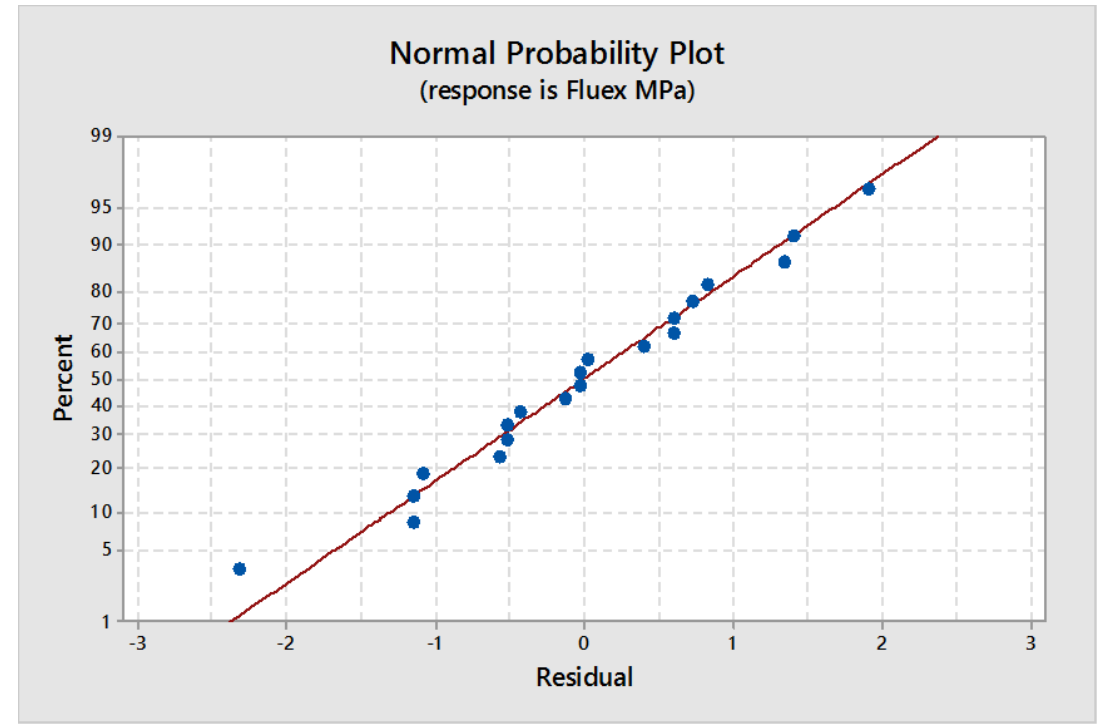

Figure 4 : Normal Probability Plot for Ultimate Flexural Strength

\subsection{Contour Plots and Response Surface of flexural strength}

Contour plot is a visual representation of a regression analysis of a three dimensional response surface on a two dimensional plane. By generating contour plots using software, the optimum values are located with reasonable accuracy by characterizing the shape of the surface. The maximum forecast value is indicated by the optimal region being the surface confined in the smallest ellipse in the contour diagram. We get Elliptical contours when the independent variables are perfectly interacted [26]. Thus, the contour plot in Fig. 6 represents the optimized flexural strength with respective fiber weight $(\%)$ and $\mathrm{NaOH}$ treatment $(\%)$ demonstrates good assosiation of ATBF/CR Biocomposites.

The response from the residual surface can be represented graphically by three-dimensional space (surface plots) that help visualize the shape of the response surface. Such a plot may be more complex for second order response surfaces than the simple series of parallel lines which may occur with first order models. Once the stationary point is located, the response surface in the immediate vicinity of the point will typically be defined by defining whether the stationary point identified is a maximum response or a low response or a saddle point.

Fig. 5, 6 and 7 are the surface plot interactions for the developed model. Response surfaces were developed for models, taking two middle-level parameters and two parameters in the $\mathrm{X}$ and $\mathrm{Y}$ axis, and the $\mathrm{Z}$ axis response. The response surfaces clearly reveal the optimum point of response. RSM is used to find the optimum set of process parameters that yield a maximum or minimum response value. The surfaces clearly reveal the optimal response point. RSM is used to find the optimum set of process parameters that yield a maximum or minimum response value. The cycle parameters corresponding to the maximal flexural tension are considered as optimal in the present investigation (analyzing and solving the contour graphs). Hence, Fig. 6 represents the optimized flexural strength of ATBF/CR Biocomposites. In one analysis it was apparent that the interfacial adhesion between fiber and matrix was significantly enhanced in composites of $15 \mathrm{wt} \%$ and obtained maximum flexural strengths of 87.5 and $93.75 \mathrm{MPa}$ respectively for 10 and $20 \mathrm{~mm}$ fiber length. This material is well stuck, with strong alignment and no high fiber defects relative to other samples. The improvement of the interfacial property was 

Cardanol Resin Polymer Composites By Response Surface Methodology

responsible for the great improvement of the mechanical properties of biocomposite cardanol [27]. While comparing to the earlier report it was clear that there is interfacial bonding among fiber and matrix was noticeably enhanced in 15.08 wt $\%$ composites obtain utmost flexural strength of $47.25 \mathrm{MPa}$ for $15.18 \mathrm{~mm}$ fiber length, correspondingly. This composite appears with a fine intent, high-quality orientation and devoid of any high irregularity of fiber, when compared to other samples. The development in the interfacial assets was accountable for the huge augmentation in mechanical properties of cardanol biocomposites

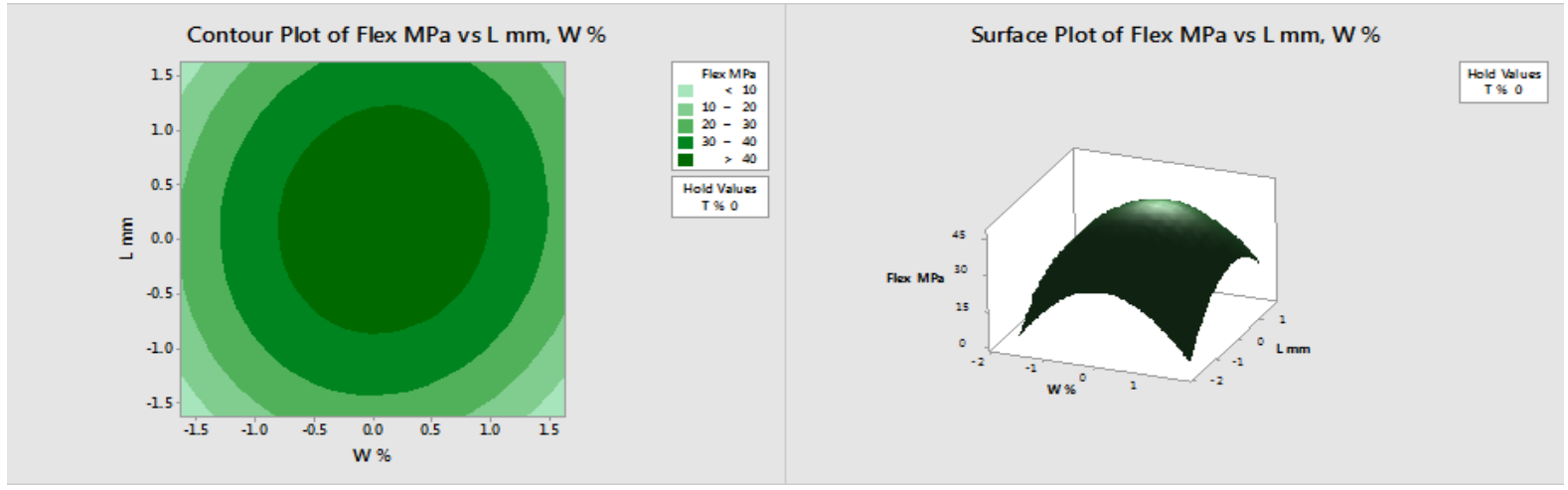

Figure 5 : Flexural Strength (MPa) Vs Fiber Length (mm), Fiber Weight (\%)

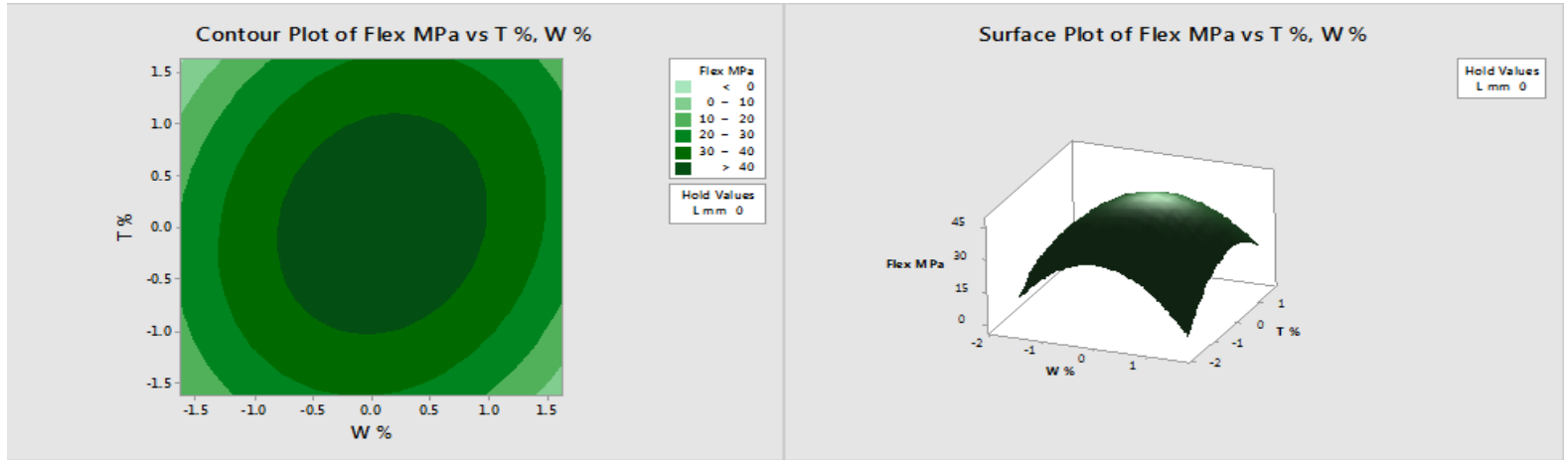

Figure 6 : Flexural Strength (MPa) Vs NaOH Treated (\%), Fiber Weight (\%)

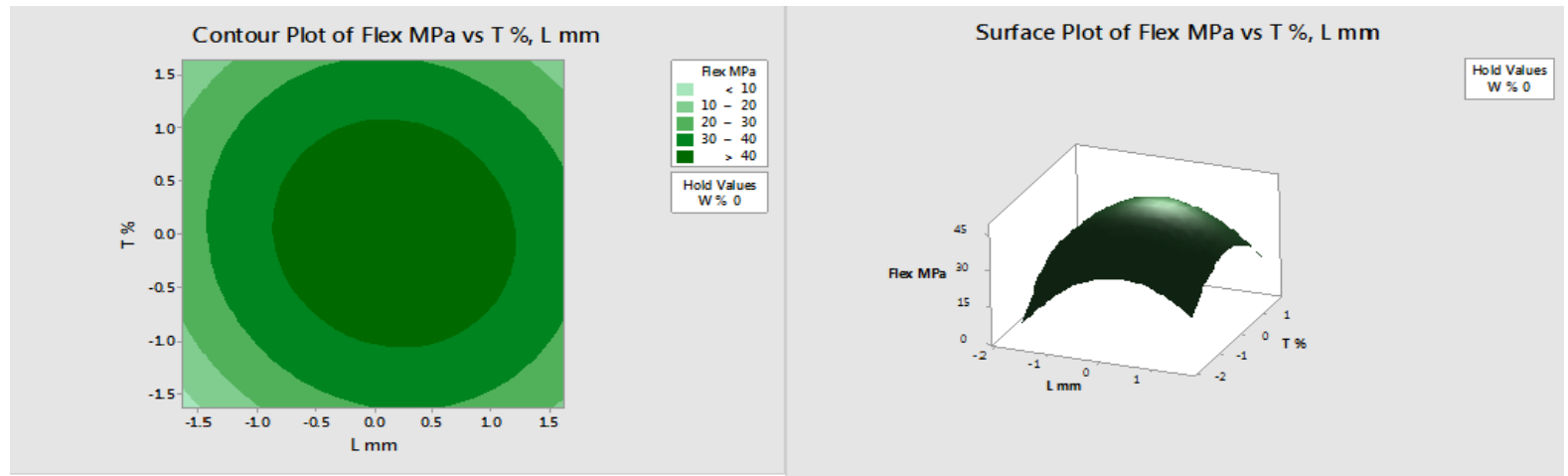

Figure 7 : Flexural Strength (MPa) Vs NaOH Treated (\%), Fiber Length (mm)

Fig.8 (a) represents the interaction plot of the Fiber weight (\%), Fiber length (mm), NaOH treatment (\%) for the output measures. The plot examines how each factor influences the flexural strength of the ATBF/CR biocomposites. Fig. 8 (b) represents the main effects plot for maximum flexural strength. The Optimisation value of combination of flexural strength is dominantly influenced by Fiber Weight (\%), NaOH treatment (\%)and Fiber length (mm). 


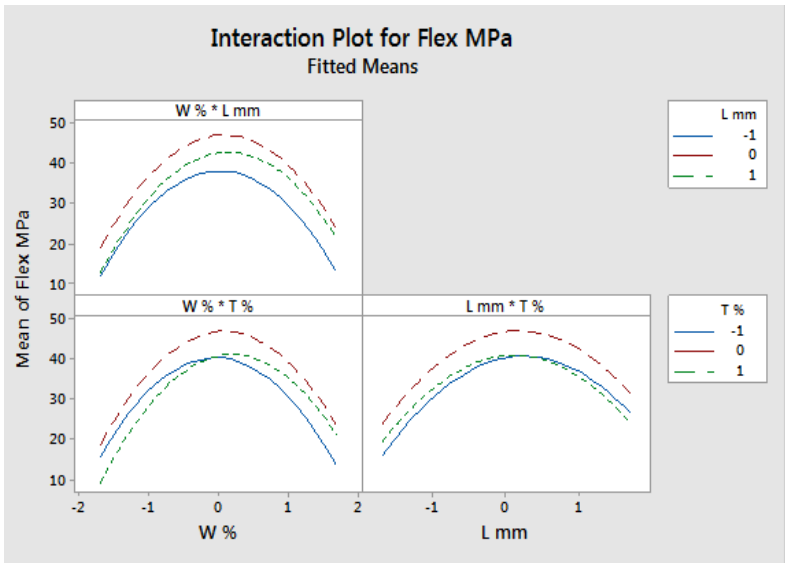

Figure 8 : (a) Interaction Plots for Flexural Strength

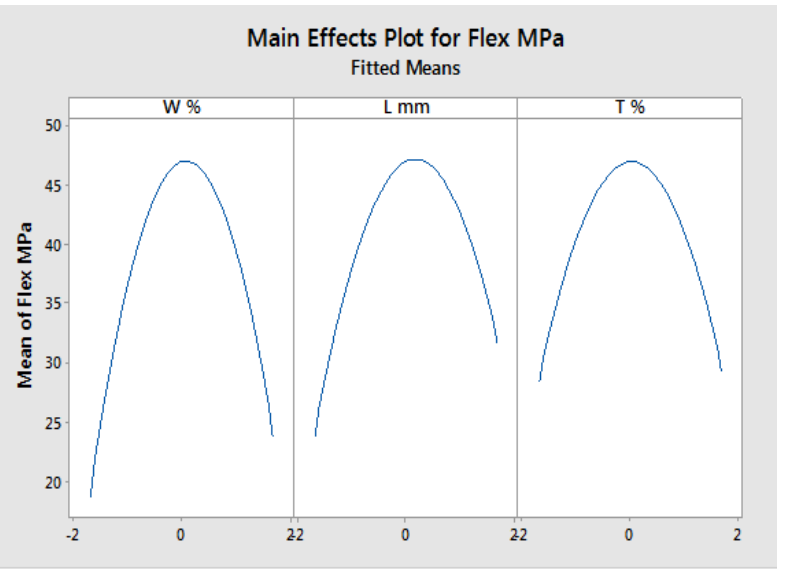

Figure 8(b) Mean Effect Plot for Max.Flexural Strength

$5 \%$ Treatment with $\mathrm{NaOH}$ has been found to increase the thermal resistance of banana fibers by eliminating waxy layers and other impurities from the surface. Banana fiber a deep hydrogen bond on treated fibers was also observed, which facilitated better mechanical properties of the fiber [28]. Similar study done inorder to check the flexural strength of ATBF/CR biocomposites the result shows $5.02 \% \mathrm{NaOH}$ treatment, flexural strength of biocomposite decreased when the the fiber length extended to 20 and $25 \mathrm{~mm}$ whereas the same flexural strength obtain maximum at fiber weight percentage of 15 but it is decreased when the fiber weight $\%$ increased to 20 and $25 \%$.

\subsection{Conditions for Optimum Response}

The optimization of flexural strength of ATBF/CR biocomposites were predicted by the second order regression equation (2). In this case, the predicted optimum combination of variables such as fiber weight $15.08 \%$, fiber length $15.18 \mathrm{~mm}$ and $\mathrm{NaOH}$ treatment $5.02 \%$ were with a desirability value of 1 as shown in Table 7, followed by Fig. 9 which represents predicted optimum condition for maximum flexural strength.

Table 7 : Optimum Condition for Maximum Flexural Strength of ATBF/CR biocomposites

\begin{tabular}{|c|c|c|c|c|c|}
\hline SI. No. & $\begin{array}{c}\text { Fiber } \\
\text { Weight }(\%)\end{array}$ & $\begin{array}{c}\text { Fiber Length } \\
\mathrm{mm})\end{array}$ & $\begin{array}{c}\text { NaOH Treatment } \\
(\%)\end{array}$ & $\begin{array}{c}\text { Tensile } \\
\text { strength(MPa) }\end{array}$ & $\begin{array}{c}\text { Desirabilityv } \\
\text { (D) }\end{array}$ \\
\hline 1 & 15.08 & 15.18 & 5.02 & 47.25 & 1 \\
\hline
\end{tabular}

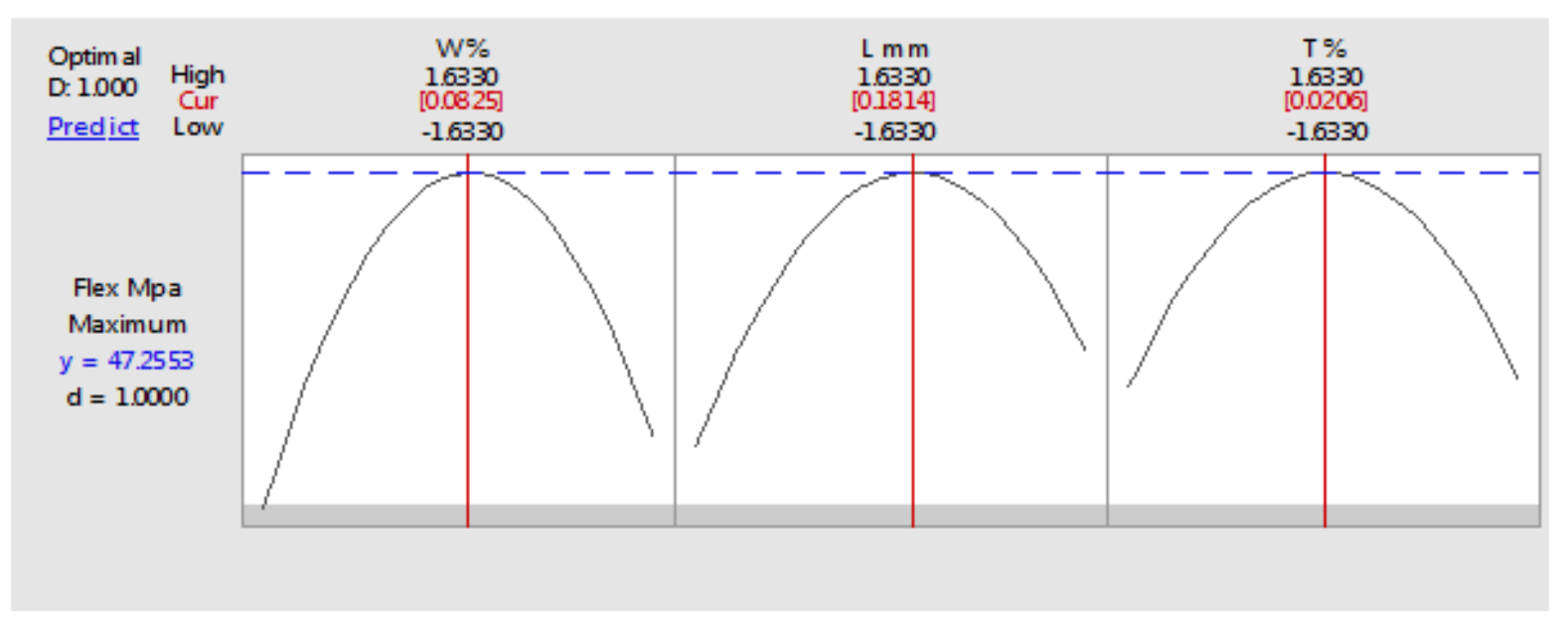

Figure 9 : Optimisation value of Flexural Strength 


\subsection{Confirmation test}

The mathematical models were validated using the validation test performed with the optimum ATBF / CR biocomposites flexural strength. Predicted values and the values the experimental confirmation test obtained were close enough. The results of the validation are summarized in Table 8 .

One validation test is conducted at the mid-levels of the process parameters to validate the model created. The calculated error is found to be small (about $1.25 \%$ ), which confirms the reproducibility of the experimental conclusion.

Table 8 : Validation of Optimised values Based on Confirmation Tests

\begin{tabular}{|c|c|c|c|c|c|}
\hline & values & $\begin{array}{c}\text { Fiber Weight } \\
(\%)\end{array}$ & $\begin{array}{c}\text { Fiber Length } \\
(\mathrm{mm})\end{array}$ & $\begin{array}{c}\text { NaOH Treatment } \\
(\%)\end{array}$ & $\begin{array}{c}\text { Tensile strength } \\
(\mathrm{MPa})\end{array}$ \\
\hline \multirow{2}{*}{$\begin{array}{c}\text { Maximum } \\
\text { Tensile } \\
\text { strength }\end{array}$} & Predicted & 15.08 & 15.18 & 5.02 & 47.25 \\
\cline { 2 - 6 } & Experimental & 15.08 & 15.18 & 5.02 & 47.85 \\
\cline { 2 - 6 } & Error \% & & & & 1.25 \\
\hline
\end{tabular}

\section{CONCLUSIONS}

Using RSM, a model was developed to predict the optimum flexural strength of ATBF / CR biocomposites. The accuracy of the model is adequate, based on the CCD test and validation test. All the estimated values were close to actual values and showed small variations with the experimental results. There by the optimised flexural strength achieved was $47.25 \mathrm{MPa}$ at the optimal values of fiber weight loading $15.08 \%$, fiber length $15.18 \mathrm{~mm}$ and $\mathrm{NaOH}$ treatment $5.02 \%$. Biocomposites with smaller fibers of fiber length $15 \mathrm{~mm}$ have shown higher flexural stiffness and strength as compared to biocomposites with larger fibers of $20 \mathrm{~mm}, 25 \mathrm{~mm}$ fiber length. The increase of the weight of fibers \% has significantly increased flexural stiffness, while slightly reducing the flexural strength.

\section{REFERENCES}

1. Ramesh, M., Palanikumar, K, Reddy, KH., 2013. Mechanical property evaluation of sisal-jute-glass fiber reinforced polyester composites. Composites Part B: Engineering. May 1;48, pp.1-9.

2. Balaji, A., Purushothaman, R., Udhayasankar, R., Vijayaraj, S,. and Karthikeyan, B., 2020. Study on Mechanical, Thermal and Morphological Properties of Banana Fiber-Reinforced Epoxy Composites. Journal of Bio-and TriboCorrosion, 6, pp.1-10.

3. Prasad, N., Agarwal, V.K., and Sinha, S., 2015. Physico-mechanical properties of coir fiber/LDPE composites: Effect of chemical treatment and compatibilizer. Korean Journal of Chemical Engineering, 32(12), pp.2534-2541.

4. Bhoopathi, R., Ramesh, M., and Deepa, C., 2014. Fabrication and property evaluation of banana-hemp-glass fiber reinforced composites. Procedia Engineering, 97, pp.2032-2041.

5. Beckermann,GW., Pickering, KL., 2009. Engineering and evaluation of hemp fiber reinforced polypropylene composites: micro-mechanics and strength prediction modeling. Compos Part A - Appl Sci Manuf 40(2):210-7.

6. Guduri, B.R., Rajulu, A.V., and Luyt., A.S., 2006. Effect of alkali treatment on the flexural properties of Hildegardia fabric composites. Journal of Applied Polymer Science, 102(2), pp.1297-1302.

7. Cao, Y., Sakamoto, S., Goda K., 2007. Effects of heat and alkali treatments on mechanical properties of kenaf fibers. In16th international conference on composite materials Jul 8, pp. 8-13. 
8. Balgude, D., \& Sabnis, A. S., 2014. CNSL: An environment friendly alternative for the modern coating industry. J. Coat. Technol. Res. 11(2),pp.169-183.

9. Gurunath, P., V., \& Bijwe, J., 2007. Friction and wear studies on brakepad materials based on newly developed resin. Wear: 263(7pp.: 1212-9.

10. Wireless, LAN., 1997.Medium Access Control (MAC) and Physical Layer (PHY) Specification, IEEE Std.;802:11.

11. Stewart R. 2008, Going green: eco-friendly materials and recycling on growth paths. Plastics Eng 64(1),pp.16-23.

12. Kaplan DL. 1998, Biopolymers from renewable resources. New York: Springer; pp.1-417.

13. Brijesh Kumar Patel., Vinod Kumar Verma, A. K., Rai \& Abhishek Gaikwad., 2017. Development of Fly Ash Based New Bio-composites Material as Wood Substitute. International Journal of Mechanical and Production Engineering Research and Development. 7: (3), pp.1-6.

14. Li J. F, Lioa H. L, Ding C. X, Coddet C. 2005. Optimizing the plasma spray process parameters of yttria stabilized zirconia coatings using a uniform design of experiments. J. Materials Processing Technology. 160:pp.34-42.

15. Mohamad, N., Muchtar, A., Ghazali, MJ., Mohd, DH., Azhari, C.H,. 2010. Epoxidized natural rubber-alumina nanoparticle composites: optimization of mixer parameters via response surface methodology. Journal of Applied Polymer Science. Jan 5;115(1):pp.183-9.

16. Nasouri, K., Bahrambeygi, H., Rabbi, A., Shoushtari, AM., Kaflou, A., 2012.Modeling and optimization of electrospun PAN nanofiber diameter using response surface methodology and artificial neural networks. J Appl Polym Sci.; 126(1):pp.127-35.

17. Deitzel, J.,M., Kleinmeye,r J., Harris DEA, Tan NB. 2001. The effect of processing variables on the morphology of electrospun nanofibers and textiles. Polymer;42(1):pp.261-72.

18. Kattamuri, N., Sung, C., 2004. Uniform polycarbonate nanofibers produced by electrospinning. Macromolecules.;3:425.

19. Parre, A., Karthikeyan, B., Balaji, A., Udhayasankar R., 2020. Investigation of chemical, thermal and morphological properties of untreated and $\mathrm{NaOH}$ treated banana fiber. Materials Today: Proceedings. Jan 1;22:pp.347-52.

20. Balaji., A, Karthikeyan, B., Swaminathan, J., 2019. Comparative mechanical, thermal, and morphological study of untreated and NaOH-treated bagasse fiber-reinforced cardanol green composites. Adv Compos Hybrid Mater 2(1),pp. 125-132.

21. Saravanan, P. and Devaraju, A., 2018. Improving mechanical properties of palm sheath composites using sodium hydroxide [naoh] treatment. Materials Today: Proceedings, 5(6), pp.14355-14361.

22. Ramires, E.C., Megiatto, J.D., Gardrat, ., Castellan, A., and Frollini, E., 2010, Biobased composites from glyoxalphenolic resins and sisal fibers, Bioresource Technology, Vol.101(6), pp.1998-2006.

23. Swaminathan, J., Ramalingam, M. and Sundaraganesan, N., 2009. Molecular structure and vibrational spectra of 3-amino-5-hydroxypyrazole by density functional method. Spectrochimica Acta Part A: Molecular and Biomolecular Spectroscopy, 71(5), pp.1776-1782. 
24. Tsimpliaraki, A., Svinterikos, S., Zuburtikudis, I., Marras, S.I. and Panayiotou, C., 2009. Nanofibrous Structure of Nonwoven Mats of Electrospun Biodegradable Polymer Nanocomposites A Design of Experiments (DoE) Study. Industrial \& engineering chemistry research, 48(9), pp.4365-4374.

25. Parre, A., Karthikeyan, B., Balaji, A., Sudhagar, P. and Udhayasankar, R., 2020. Forecasting the Finest Firmness of Biocomposites using Response Surface Design Methodology.

26. Hussin A.S.M., Farouk A.E.A., Greiner R., 2012. Optimization of Cultivation Conditions for the Production of Phytate-Degrading Enzymes by Enterobacter Sakazakii ASUIA279 Isolated from Malaysian Maize Root, Journal of Biotechnology and Biodiversity. 3(2):pp.1-10.

27. Balaji, A., Sivaramakrishnan, K., Karthikeya., B., Purushothaman, R., Swaminathan, .J, Kannan, S., Udhayasankar, R., Haja Madieen, A., 2019. Study on mechanical and morphological properties of sisal/banana/coir fiber-reinforced hybrid polymer composites. J Braz. Soc Mech Sci 41(9):386.

28. Lin, J.C., Chang, L.C., Nien, M.H. and Ho, H.L., 2006. Mechanical behavior of various nanoparticle filled composites at low-velocity impact. Composite Structures, 74(1), pp.30-36.

29. Udhayasankar, R. and Karthikeyan, B., 2019. Processing of cardanol resin with CSP using compression molding technique. Materials and Manufacturing Processes, 34(4), pp.397-406.

30. Udhayasankar, R., Karthikeyan, B. and Balaji, A., 2018. Coconut shell particles reinforced cardanol-formaldehyde resole resin biocomposites: Effect of treatment on thermal properties. International Journal of Polymer Analysis and Characterization, 23(3), pp.252-259.

31. Jawaid, M., Khalil, H.A., Bakar, A.A. and Khanam, P.N., 2011. Chemical resistance, void content and tensile properties of oil palm/jute fibre reinforced polymer hybrid composites. Materials \& Design, 32(2), pp.1014-1019. 
